УДК 678.6.004

\title{
НОВЫЕ ПОДХОДЫ К ОРГАНИЗАЦИИ ЭКОЛОГО-ЭКОНОМИЧЕСКИ ЭФФЕКТИВНОГО УПРАВЛЕНИЯ УТИЛИЗАЦИЕЙ ТВЁРДЫХ БЫТОВЫХ ОТХОДОВ
}

\author{
(C) 2012 г. К. В. Сафронова
}

\section{Новочеркасская государственная мелиоративная академия}

Ежегодньй неуклонный рост объемов образующихся отходов - острая сочиальноэкономическая и экологическая проблема. Переработка отходов в России не занимает какого-либо серьезного положения в сфере производства, хотя мировая практика показывает все возрастаюшую роль этой отрасли не только в экологии, но и в экономике. Несомненно, что данный вид услуг по своему потенцилалу наиболее перспективен. В настоящее время одной из основных проблем, стоящих перед коммунальными хозяйствами практически всех стран, является утилизачия отходов. Это требует проведения соответствующих мероприятий как в области законодательства, так и в практической деятельности. Некоторым соображениям по этому поводу посвящена настоящая статья.

Ключевые слова: безотходность производства; отходы; переработка; потребление; ресурсы; свалки; экология; окружающая среда; ресурсосбережение.

Steady increasing of the annual waste generation is an actual social, economic and environmental problem. Recycling in Russia doesn't play an appreciable role in the sphere of production, although the world practice shows the ever-increasing role of the industry not only in the environmental safety, but also in the economy. There is no doubt that this type of service has a great potential. At present, one of the main problems facing the communal services of almost all countries is the disposal of wastes. This situation requires the appropriate measures in the field of legislation and in practice. Some ideas on the subject are presented in the article.

Key words: waste production; waste; processing; consumption; resources; dump; ecology; environment; resource conservation.

Рациональное использование ресурсного потенциала экономики на основе снижения материалоемкости выпускаемой продукции, бережного расходования сырья, топлива, энергии, вовлечения в хозяйственный оборот отходов производства и вторичных ресурсов становится одной из самых актуальных проблем в условиях развития современной России. Бурное развитие научно-технического прогресса за последнее столетие привнесло в жизнь общества немало благ, которые способствовали повышению уровня и комфортабельности жизни, улучшению благосостояния людей. Но данное развитие имеет и обратную сторону, сопровождаемую интенсификацией добычи природных ресурсов и увели- чением количества выбросов загрязняющих веществ, повлекшими за собой ухудшение состояния окружающей среды. Для России сегодня серьезную проблему представляют твердые бытовые отходы (ТБО). Твердые бытовые отходы представляют определенную опасность для здоровья всех граждан и для окружающей природной среды. Окружающая среда является необходимым условием осуществления репродукции человека как биологического вида живого организма. Исходя из этого масса накапливаемых твердых бытовых отходов даже по отдельным городам, не говоря о стране в целом, достигает гигантских величин, поэтому размещение и обезвреживание отходов - серьезная про- 
блема. Как известно, проблема твердых бытовых отходов (ТБО), или попросту мусора, становится все более животрепещущей. Хотим мы этого или нет, но современная жизнедеятельность человека сопровождается образованием большого числа таких отходов, и своевременное их удаление является одним из важнейших условий нормального жизнеобеспечения.

Все это говорит о том, что вопросы сбора и утилизации мусора уже не могут рассматриваться просто как проблемы муниципального уровня: необходима разработка и реализация полноценной государственной политики в этой области.

С нашей точки зрения, политика государства в области отходов должна базироваться на следующих принципах:

- минимизация экологического ущерба;

- максимальный рециклинг материалов и энергии;

- недопущение образования вторичных отходов при переработке;

- минимально возможные затраты.

Вовлечение вторичного сырья и отходов в производственный оборот обеспечивает также значительный экологический и социальный эффект: сокращается ущерб от загрязнения окружающей среды различными видами отходов, высвобождаются земли, занятые отвалами, появляется возможность создания дополнительных рабочих мест. В этой связи возникает необходимость исследования проблем эколого-экономической эффективности использования и переработки твердых бытовых отходов в современных условиях. Для этого требуются новые экономические подходы, совершенствование действующего экономического механизма использования твердых бытовых отходов и создание организационных и экономических условий для сбора и переработки ТБО в качестве сырья. Ситуация с твердыми бытовыми отходами относится к числу наиболее сложных экологических проблем. Основные технологические трудности связаны с высокой энергоемкостью переработки отходов и вредным воздействием на окружающую среду обеспечением необходимой чистоты конечных продуктов.

Переработка отходов - деятельность, связанная с выполнением технологических процессов по обращению с отходами для обеспечения повторного использования в народном хозяйстве полученных сырья, энергии, изделий и материалов. Утилизация отходов - деятельность, связанная с использованием отходов на этапах их технологического цикла, и/или обеспечение повторного (вторичного) использования или переработки списанных изделий [8].

Твердые бытовые отходы (ТБО) являются многотоннажными отходами потребления (отслужившие свой срок в быту товары и изделия, а также ненужные человеку продукты и их остатки, образовавшиеся в системе городского хозяйства). Проблема твердых бытовых отходов (ТБО) является весьма актуальной, поскольку ее решение связано с необходимостью обеспечения нормальной жизнедеятельности населения, санитарной очистки городов, охраны окружающей среды и ресурсосбережения [4].

Одной из наиболее значимых проблем современности в мире является проблема обращения с отходами производства и потребления. Не менее актуальна она и для Российской Федерации. Скопившиеся на территории нашей страны отходы, свалки, захоронения высокотоксичных и ядовитых веществ следует рассматривать как накопленный за многие десятилетия экологический ущерб. Общий объем накопленных неутилизированных отходов оценивается приблизительно в 82 млрд. т. На территории Российской Федерации насчитывается около 11 тыс. полигонов и свалок. При этом средний уровень вторичного использования промышленных отходов составляет 35\%, твердых бытовых - 3-4\%.

В результате низкого уровня вовлечения отходов в хозяйственный оборот происходит постоянное накопление неиспользуемых отходов.

Из-за несоответствия многих объектов складирования и захоронения отходов действующим экологическим и санитарным нормам происходит их негативное воздействие на окружающую природную среду. По мере расширения масштабов приватизации объектов размещения отходов (свалок) возрастает угроза потери государственного контроля над ростом стоимости услуг по обезвреживанию и захоронению отходов, в то время как экологическая опасность таких объектов продолжает оставаться высокой. 
Неудовлетворительное состояние в сфере обращения с отходами вызвано низкой степенью утилизации отходов, причиной чего является, в том числе, нехватка специализированных мощностей по их обезвреживанию и переработке.

Так, по данным Роспотребнадзора в Российской Федерации функционирует 7 мусоросжигательных, 5 мусороперерабатывающих заводов и 39 мусоросортировочных комплексов. В то же время существуют примеры, когда действующие предприятия по обезвреживанию отходов простаивают, так как отходы на них не поступают.

Необходимо сформировать единую Концепцию обращения с отходами производства и потребления на территории России, перейти к прогнозированию объемов переработки отходов для различных отраслей промышленности и жилого сектора. Не менее важно и осуществлять в этой сфере единую научно-техническую и инновационную политику. Часто повторяемое слово «единый» говорит об острой необходимости объединения созидательных сил государства в противоборстве с мусором, поглощающим страну. Мы должны уже сегодня предпринять энергичные усилия, чтобы предотвратить экологическую катастрофу и создать гармоничную среду обитания для наших потомков [3].

В условиях рыночной экономики, требующей мобилизации всех резервов хозяйствования, задачи материалосбережения становятся еще более актуальными. Одним из важнейших направлений материалосберегающей деятельности производственных структур является работа с образующимися отходами. Статья включает целую совокупность мероприятий по прогнозированию и профилактике образования отходов, а также поиску и реализации возможностей их более эффективного использования. Рациональное применение отходов производства позволяет решать множество экономических и экологических проблем, в том числе расширять сырьевую базу экономики, увеличивать объемы выпуска продукции, снижать себестоимость хозяйствования, предотвращать загрязнение среды.

Экологизация экономики является не только особым направлением деятельности бизнеса и экономической политики, но и об- щей характеристикой инновационного развития экономики, тесно связанной с повышением эффективности ресурсопотребления.

В результате повышения технологической и экологической эффективности экономики к 2020 году предполагается снижение уровня «экологического воздействия» в 22,5 раза, что позволит выйти на современные показатели сбережения природы развитых европейских стран. При этом уровень экологических издержек (затрат на снижение вредных выбросов, утилизацию отходов и восстановление природной среды) может возрасти до 1-1,5\% ВВП в 2020 году [6]. Переход к рыночной экономике предопределяет коренное преобразование масштабного загрязнения территорий. С одной стороны, государство не поддерживает честных предпринимателей и выгодно работать нечестно, а с другой полностью отсутствует система экологического контроля. В статье рассмотрены проблемы и формы хозяйствования в современных условиях.

В природе производство осуществляется по замкнутому циклу. Оно безотходно. Конечный продукт производственной деятельности становится исходным для нового производственного цикла. В отличие от природного, человеческое производство в своей массе и своей основе является отходным. Иначе говоря, конечный продукт производства не является и не становится исходным для следующего цикла, а поступает в отходы. Подсчитано [9], что для жизнедеятельности человека необходимо в год расходовать не менее 20 т природных ресурсов. Из них лишь 5-10\% идут на продукцию, а 90-95\% поступает в отходы. Чрезвычайной отходностью человеческого производства создается загрязнение окружающей среды вредными, нехарактерными для природы веществами, что ведет к преждевременному истощению природной среды и, в конечном счете, к разрушению экологических систем природы.

Проблема отходов производства и потребления в нынешних условиях является одной из наиболее сложных. По вопросу размещения и переработки промышленных и бытовых отходов и одновременного увеличения топливных и энергетических ресурсов возникает необходимость поиска альтернативных источников сырья, выработку которых воз- 
можно осуществлять путем утилизации отходов производства и потребления.

Однако в условиях очевидного истощения природных ресурсов отходы можно и нужно рассматривать в качестве техногенных месторождений, переработка которых позволяет решать как экономические, так и экологические проблемы.

Заместитель директора департамента государственной политики и регулирования в сфере охраны окружающей среды и экологической безопасности Минприроды РФ Н. Нефедьев напомнил, что в апреле 2012 г. президент утвердил основы государственной политики в области экологического развития России на период до 2030 г., в которых в том числе есть блок, посвященный отходам. Кроме того, сейчас готовится ко второму чтению в Госдуме законопроект о внесении изменений в закон об отходах, которым планируется ввести ряд налоговых льгот для переработчиков мусора, установить ответственность производителя в этой сфере и повысить инвестиционную привлекательность отрасли.

В России в первую очередь необходимо создать инфраструктуру, предназначенную для привлечения в хозяйственный оборот бытовых отходов, которая позволила бы осуществлять раздельный сбор мусора, обработку этих материалов и создание вторичной продукции или вторичного сырья для производства первичной продукции.

Для того чтобы решить подобные проблемы, например, в Германии потребовалось 20 лет. В этом случае к 2032 г. около 40\% всех бытовых отходов должно будет отправляться на захоронение, а 60\% - перерабатываться и обезвреживаться [14].

В Германии (первой из европейских стран) с 7 октября 1996 г. вступил в действие «Закон о замкнутых циклах хозяйственной деятельности и отходах», который позволил еще больше активизировать рынок экологических услуг в области переработки отходов. В частности, удалось: добиться снижения объема образования и таким образом «спровоцировать» возникновение конкуренции за отходы среди предприятий по их переработке; стимулировать замену используемого первичного сырья на вторичные материальные ресурсы; создать условия, благоприятствующие переходу к новой системе хозяйство- вания [7]. Чисто экономические показатели в условиях рынка трансформировались в эколого-экономические. Теперь при производстве одинаковой продукции и сохранении ее качества преимущество получает та фирма, которая сумела минимизировать количество требующих утилизации отходов.

Впервые в России проведена инвентаризация свалок и ТБО, и создана база данных, включающая следующую информацию: наименование свалки, местоположение, год начала эксплуатации, год закрытия или планируемого закрытия, размеры (площадь, высота или глубина), наличие/отсутствие природоохранных сооружений, объем и масса ежегодно размещаемых отходов, объем и масса накопленных отходов, владелец свалки и его контактная информация, расчетная оценка количества образующего свалочного газа и метана. Созданная база данных является максимально полной на сегодняшний день и включает все крупные свалки. Общее количество учтенных свалок составляет 865 . Общее количество отходов, размещаемых на представленных в базе данных свалках, составляет 122,4 млн. м ${ }^{3}$, или 24,6 млн. т в год. Количество накопленных отходов на учтенных свалках составляет 354 млн. т. Хотя составленная база данных является на сегодняшний день наиболее полной, по нашему мнению она не отражает общего количества свалок на территории России. Спецификой России является наличие свалки практически в каждом населенном пункте: в крупных городах может быть размещено несколько свалок, в малых городах и поселках - по одной. Эти свалки, как правило, отнесены к санкционированным, то есть легальным. Кроме этого, на территории всех российских регионов имеется множество несанкционированных свалок. Нами выполнена дополнительная оценка общего количества свалок с использованием как созданной нами базы данных, так и дополнительно собранной информации о количестве санкционированных и несанкционированных свалок по регионам. Установлено, что общее количество санкционированных свалок ТБО на территории РФ составляет более 15 тысяч, количество учтенных несанкционированных свалок - около 10 тысяч. Таким образом, общее количество свалок составляет около 25 тысяч [12]. 
Образование несанкционированных свалок и недостаточно эффективная их ликвидация сопряжены с рядом проблем законодательного и организационного характера.

Отсутствие мест для сбора отходов ведет к возникновению несанкционированных свалок в прилегающих лесных массивах, полях и оврагах, к захламлению отходами территорий в местах массового отдыха горожан, вокруг садовых и дачных участков, вдоль автомобильных и железных дорог.

Следует отметить проблему нежелания подведомственных администрациям муниципальных образований учреждений (как правило, МУП) заниматься обустройством имеющихся мест размещения ТБО [5].

Не уделяется внимание передовым технологиям сортировки мусора, а ведь технология сортировки и прессования ТБО является основой построения экологически безопасной и высокодоходной системы утилизации отходов. Срок эксплуатации полигонов может продлеваться в два-три раза, высотных - в 4-10 раз. Сокращаются площади под полигоны, упрощается их формирование, резко сокращается количество техники и рабочей силы на полигонах. Исключаются характерные для утилизации твердых бытовых отходов экологические проблемы [10].

Чисто экономические показатели можно трансформировать в эколого-экономические условия. Рассмотрим в обобщенном виде производство с позиций «жизненного цикла» (ЖЦ) продукции. Жизненный цикл начинается с ресурсов $(P)$, которые включают сырье для производства продукции $(\mathrm{Cn})$ и энергии $($ Ээ). Продукция $(П р)-$ все, что обеспечивает жизнедеятельность человека, в том числе тепло, свет и т. п., заканчивается цикл либо утилизацией, либо захоронением. В процессе «жизни» продукция стареет, теряя потребительские свойства. Кроме того, при получении, транспортировке и эксплуатации в окружающую среду попадают продукты «жизнедеятельности» в виде отходов, сбросов, выбросов и т. Д., все это - некий остаток, не нашедший полезного применения. Если применить его за какую-то общую категорию-остаток, то получим простое выражение:

$$
P=\Pi p+O c
$$

где $P$ - ресурсы; Пр - продукция; $O c-$ остаток.

Ресурсы разделяются возобновляемые (Рвз), минеральные (ископаемые) или первичные $(P n)$ и вторичные $(P r)$. Ресурсы возобновляемые вписываются в естественный круговорот в природе, поэтому в наших рассуждениях их можно рассматривать в составе ресурсов в целом. Тогда получим:

$$
P=P n+P b \text {. }
$$

Политика ресурсосбережения требует увеличения доли ресурсов вторичных и уменьшения ресурсов первичных. Это означает, что в каждой отрасли, для каждого вида продукции должен быть некий лимит. Pеализация подобного механизма ресурсосбережения возможна административными (законодательство) и экономическими методами. Суть первого, по-видимому, не требует комментариев. Решение проблемы экономическими методами наличествует в том случае, когда фактическое количество отходов ниже установленного лимита для данного вида продукции. Положительная разница в выражении «лимит установленный минус лимит фактический» - сэкономленная часть первичных ресурсов.

Интересные идеи по организации подобного управления в области отходов предложены в работе А. Ф. Богачева [1]. Такой подход инициирует создание специализированных производств и предприятий, базирующихся только на использовании вторичного сырья. Из всего объема производственных отходов промышленными методами у нас перерабатывается не более 3-7\%, остальные поступают на полигоны, а если быть точнее - на свалки.

По прогнозам специалистов, в России объем накапливаемых за год ТБО в ближайшие 10-15 лет увеличится в 1,5-2 раза. Уже сейчас увеличение количества отходов превышает темпы роста промышленного производства, а по стоимости отходы приравнивают к $17-18 \%$ ВВП.

Во-первых, отходы представляют собой один из самых мощных источников загрязнения окружающей среды.

Во-вторых, отходы становятся самым богатым сырьевым ресурсом с высоким экономическим потенциалом.

Сегодня в России есть понимание, что 
следует законодательно установить ответственность производителя за утилизацию его отслужившей продукции. Требуется также совершенствование технологии сбора, сортировки и переработки мусора - это одна из ключевых проблем. Однако есть и объективные причины неразвитости этого сегмента экономики. По заключению Федеральной антимонопольной службы (ФАС), в 45\% городов страны эту работу выполняет один хозяйственный субъект, как правило, муниципальный, в 39\% городов - по 2-3 предприятия. При отсутствии конкуренции у нас пока не приживается раздельный сбор мусора, без чего становление серьезного бизнеса по переработке мусора невозможно [13].

К примеру, в переработке полимеров рентабельность достигает 1000\%. Пластиковая бутылка или канистра весит мало, а объем занимает большой. Если бутылки из полиэтилентерефталата (ПЭТФ) просто прессовать, то они будут стоить 100 долл./т. Если бутылки помыть и порезать на чипсы, то тонну берут за 300 долл., а тонна гранул из ПЭТФ стоит уже тысячу долларов. Если же производить нити для текстильной промышленности или ткань для дорожного строительства, то тонна ПЭТФ будет стоить уже 2500 дол. [2]. Также обстоит дело и с макулатурой. В середине 90-х годов прошлого века ее никто не собирал, потому что бумагу в Россию импортировали из Финляндии.

По усредненным данным, качественный состав ТБО по массе (в \%) выглядит следующим образом: пищевые и органические отходы - 40, макулатура - 35, стеклобой - 3, полимеры - 6, резина, кожа, текстиль - 1 , дерево - 2, прочие - 9 [11].

Однако спрос на вторичное сырье значительно превышает возможности существующих отходоперерабатывающих предприятий. В Госдуме 7 октября 2011 года обсуждался и был принят в первом чтении законопроект «О внесении изменений в Федеральный закон «Об отходах производства и потребления». Основная цель этого законопроекта - coздать экономические стимулы по вовлечению отходов в хозяйственный оборот в качестве вторичных ресурсов. Главное революционное предложение, внесенное разработчиками данного документа - возложить ответственность за дальнейшую судьбу продукции, утратившей потребительские свойства, на ее производителей: обязать их утилизировать, обезвреживать или направлять мусор на вторичное использование. Эта мера, безусловно, на пользу отходоперерабатывающей отрасли и будет способствовать активизации спроса на рециклинговые услуги.

С 2017 года вводится запрет на захоронение отходов, которые могут быть использованы в качестве вторичного сырья (вторичных материальных ресурсов): металлолома, стеклянной и пластиковой тары, автомобильных шин и аккумуляторов и других видов отходов.

Подводя итог сказанному, необходимо сформулировать следующие основные выводы:

1. Для обеспечения экологической эффективности системы переработки вторичного сырья, основанной на рыночных отношениях, необходимо создание комплексной системы регулирования рынка вторичного сырья. Эта проблема должна решаться не только муниципальными и государственными органами власти - необходим механизм государственно-частного партнерства, в рамках которого возможно привлечение на конкретной основе представителей частного сектора экономики для более эффективного и качественного решения задач в сфере обращения с отходами.

2. Одна из важнейших задач цивилизованного общества - создание индустрии вовлечения вторичных ресурсов в производство новых товаров. Существующий технологический уровень позволяет перерабатывать и неоднократно использовать практически любые отходы.

3. Очень благоприятной деятельностью для инвестиций является бизнес по переработке мусора. Во-первых, мусороперерабатывающих компаний относительно немного, тогда как самого сырья хватает на всех - на одного человека приходится около 250 кг бытовых отходов в год [15]. Во-вторых, предприниматель может организовать приём различных типов мусора. Сегодня классический подход к утилизации отходов (в контейнер - на свалку - рекультивация) становится малоэффективным, а также потенциально опасным - токсичные отходы представляют определённую угрозу для экологии и здоро- 
вья человека. Государственная власть и городская администрация благосклонно относятся к предприятиям, перерабатывающим отходы. Таким образом, бизнес по переработке мусора является выгодным и инвестиционно-привлекательным.

\section{Литература}

1. Богачев А. Ф., Воронов А. А., Пименов $A$. H. Биржевая система инвентаризации и перераспределения отходов производства. Эколого-экономические предпосылки и организационные задачи. // Инженерная экология. - 1996. - №4. - С. 18.

2. Данилевский А. Ф. Возрождение земли. // Ваш консультант. - 2007. — №1-2. - С. 5-6.

3. Проблемы формирования отходоперерабатывающей индустрии в Российской Федерации. Всероссийская конференция. // Информационно-аналитические материалы. - M., 2011.

4. Девяткин В. В. Отходы как вторичные материальные ресурсы. // Экология производства. - 2007. - №2. - С. 44-51.

5. Экологические вопросы территориального планирования. // Правовая защита. 2011. — №17 (23).

6. Концепция долгосрочного социальноэкономического развития Российской Федерации от 26 мая 2008.

7. Klett $W$. Задачи менеджмента в области в области удаления отходов. // Научно-технические аспекты окружающей среды. - 1999. - №1.

8. Межгосударственный стандарт ГОСТ
30772-2001 «Ресурсосбережение. Обращение с отходами. Термины и определения» (введен в действие Постановлением Госстандарта РФ от 28 декабря 2001 г. №607-ст). // Официальное издание Госстандарта России, ГУП ЦПП, 2003.

9. Нефедьев Н. Б. Организационно-методические вопросы оценки количеств парниковых газов на российских полигонах ТБО. // Материалы международного семинара «Коммерческое использование свалочного газа». - М., 2007. - C. 40-44.

10. Приложение №1 к протоколу заседания Департамента Росприроднадзора ЮФО от 18.04.2012 г.

11. Сапожникова Г. Выбрасывать с умом. // Отечественные записки. - 2007. - №2. C. 107-114.

12. Шемшученко Ю. С. Правовые проблемы экологии. - К.: Наукова думка, 1989. - C. 12.

13. Твердые бытовые отходы [Электронный ресурс] / Отраслевой электронный портал. - Режим доступа: http://www.solidwaste. ru/publ/12.html4, свободный. - Загл. с экрана.

14. Петрова К. Россия очистится от мусора уже к 2032 г. [Электронный ресурс] / РосБизнесКонсалтинг. - Режим доступа: http://top.rbc.ru/economics/07/06/2012/654050. shtml, свободный. - Загл. с экрана.

15. Росприроднадзор - за сжигание мусора [Электронный ресурс] / Экология и жизнь. - Режим доступа: http://www.ecolife. ru/infos/agentstvo-ekoinnovatsijj/8242, свободный. - Загл. с экрана.

25 ноября 2012 г. 


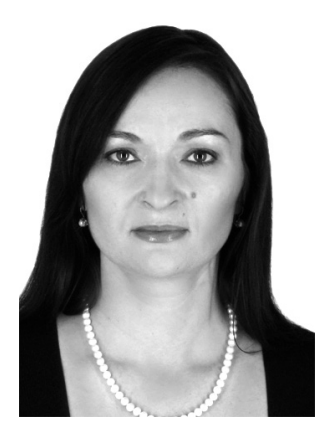

Ксения Валентиновна Сафронова - соискатель Новочеркасской государственной мелиоративной академии (научная специальность 08.00.05 «Экономика и управление народным хозяйством»).

Ksenia Valentinovna Safronova - competitor for the Candidate's degree at the Novocherkassk State Academy of Land Reclamation (research specialization 08.00.05 «Economics and Management for National Economy»).

346400 , г. Новочеркасск, ул. Пушкинская, 111

111 Pushkinskaya st., 346400, Novocherkassk, Rostov reg., Russia

Тел.: +7 (8635) 27-96-36; e-mail: safronova.s-k-v@yandex.ru

\section{IX заочная Международная научно-практическая конференция «Тенденции и инновации современной науки»}

Место проведения: Россия, г. Краснодар

Сроки проведения: прием тезисов - до 22 августа 2013 г.; рассылка сборников - до 24 сентября 2013 г.

Организатор: Научно-издательский центр «Априори», г. Краснодар

Контактный телефон: +7 (918) 180-98-79

E-mail: info@apriori-nauka.ru

Подробности и условия участия на сайте:

www.apriori-nauka.ru 